\title{
A ética da pesquisa em seres humanos e a publicação de artigos científicos
}

\author{
TRAJANO SARDENBERG ${ }^{1}$
}

O avanço da medicina rumo à determinação de novos tratamentos clínicos e cirúrgicos e novos métodos de diagnósticos envolve a experimentação em seres humanos. A experimentação em animais não humanos, os modernos modelos matemáticos e estatísticos e o uso intensivo da informática não conseguiram excluir a fase final de experimentar em seres humanos.

O rigor científico, refletido no rigoroso delineamento da pesquisa, há que ser obedecido em qualquer tipo de experimento. Modelos matemáticos para determinação do número de amostra, randomização, uso de placebo, wash-out, duplo-cego, tempo de seguimento e etc. são aspectos rotineiramente aplicados e avaliados nos experimentos em seres humanos.

O uso de seres humanos em experimentos científicos traz inegáveis benefícios para a sociedade. No entanto, há sempre o conflito entre o indivíduo submetido à experimentação e a ciência ${ }^{(1)}$.

A ciência não está isolada da sociedade e, portanto, sofre influências políticas, econômicas, ideológicas, étnicas e etc. O s experimentos conduzidos por médicos alemães durante 0 regime nazista, em prisioneiros raciais, políticos e militares é o maior exemplo do século $X X$ em que a balança pendeu radicalmente para o interesse da "sociedade" em detrimento dos interesses do indivíduo.

Devemos sempre lembrar que o objetivo da pesquisa é melhorar a saúde e o bem-estar dos pacientes e nunca causar danos ou submetê-los a graves riscos para obter esses objetivos ${ }^{(2)}$.

Apesar da regulamentação institucional da pesquisa em seres humanos no ano de 1900 na antiga Prússia(3), o primeiro documento internacional sobre esse tema é o Código de Nuremberg(4), editado pelo Tribunal de Nuremberg em 1947, no qual constam 10 itens com recomendações que os médicos devem seguir nos experimentos em seres humanos.

1. Professor Assistente do Departamento de Cirurgia e Ortopedia da Faculdade de Medicina de Botucatu - UNESP. Presidente da Comissão de Ética Médica da FMB - UNESP. Membro do Comitê de Ética em Pesquisa em Seres Humanos da FMB - UNESP.

Endereço para correspondência - Trajano Sardenberg, Departamento de Cirurgia e Ortopedia, Faculdade de Medicina de Botucatu UNESP - 18618-970 - Botucatu, SP. Fax: (014) 821-4615, e-mail: tsarden@fmb.unesp.br
O primeiro tópico explicita: “o consentimento voluntário dos sujeitos humanos é absolutamente necessário".

Em 1964, a Assembléia Médica Mundial aprovou a Declaração de Helsinque cuja última edição foi aprovada na 48ạ Assembléia Geral na República da África do Sul em 1996 (5).

Em nosso país, em 1996, o Conselho Nacional de Saúde aprovou a Resolução 196/96(6), que regulamenta a pesquisa em seres humanos no Brasil. Referendada em vários documentos nacionais e internacionais, inclusive a Declaração de H elsinque, a Resolução 196/ 96 incorporou vários conceitos da bioética e reafirmou o consentimento livre e esclarecido dos indivíduos para participarem de pesquisas científicas e a aprovação prévia dos protocolos por comitê independente.

A pesar de haver vários elos de ligação entre os aspectos científicos e os aspectos éticos da pesquisa clínica, como por exemplo, em estudos com número de amostra e randomização inadequados, haverá a participação de seres humanos em experimentos cujos resultados não terão validade científica, os aspectos especificamente relacionados à ética da pesquisa em seres humanos são, muitas vezes, colocados em segundo plano durante o delineamento e execução do estudo.

Alguns pesquisadores reconhecem a importância dos aspectos éticos na pesquisa, porém manifestam preocupações com a institucionalização do estabelecimento de regras nessa área, argumentando que se trata de mais uma tentativa de controlar e reprimir os pesquisadores, além de ser imposição do governo e que reprime a criatividade dos pesquisadores. No entanto, estas regulamentações não foram impostas por governos, mas sim elaboradas principalmente por médicos pesquisadores para proteger os pacientes e garantir a qualidade das pesquisas ${ }^{(2)}$.

A política editorial de parte de nossas revistas científicas reflete a primazia da técnica em relação à ética na pesquisa clínica. Em estudo realizado por nós(7) observamos que em 139 periódicos brasileiros, aproximadamente $80 \%$ não fazem qualquer referência a aspectos éticos nas suas instruções aos autores. O J ornal de Pneumologia solicita nas Instruções Redatoriais que "Sempre que pertinente, declarar no texto que o trabalho foi aprovado pela Comissão de Ética do Hospital".

As orientações do Comitê Internacional de Editores de Revistas M édicas, expressas nos "R equisitos U niformes para Manuscritos Submetidos a Revistas Biomédicas"(8), são con- 
sideradas frágeis ${ }^{(9)}$, ao afirmarem explicitamente: “ao relatar experimentos com seres humanos, indique se os procedimentos foram realizados de acordo com os padrões éticos do comitê responsável por experimentação humana e com a Declaração de Helsinque de 1975, tal como revista em 1983".

A publicação ou não de artigos considerados eticamente inadequados é polêmica antiga no meio científico editorial. Um dos aspectos levantados seria que ao não publicar artigos eticamente questionáveis, estar-se-ia criando a falsa impressão de que estudos não éticos não estariam sendo realizados. A alternativa seria publicar, em caráter excepcional, o artigo não ético porém com relevância científica, junto com

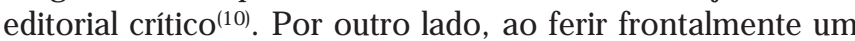
dos princípios da Declaração de Helsinque ("resultados de pesquisa realizadas em desacordo com os princípios da Declaração não devem ser publicados"), essa postura encontra adversários importantes, como por exemplo, os editores do J ournal of the American Medical Association ${ }^{(9)}$ e do J ournal of Bone and J oint Surgery ${ }^{(11)}$. B eecher ${ }^{(12)}$, professor de Pesquisa em Anestesia na Escola Médica de Harvard, exprime opinião de que artigos não éticos não devem ser publicados, o que seria fator desencorajante para a realização desses experimentos, e afirma ainda que a publicação de artigo não ético junto com editorial crítico teria que ser feito com excepcional habilidade para evitar o odor da hipocrisia.

0 estabelecimento de orientações éticas precisas e claras acoplado à exigência de que os autores dos artigos informem os procedimentos éticos adotados no desenvolvimento da pesquisa, principalmente a obtenção do consentimento esclarecido e a aprovação por comitê independente, significaria que a revista científica privilegia os pesquisadores preocupados com a ciência e a ética(9).

A luz da ética iluminando o caminho da ciência é o ideal que devemos almejar ativamente. Portanto, a busca desse ideal deve ser realizada com a participação efetiva de todos os parceiros da ciência, entre eles os pesquisadores, agências financiadoras, editores e leitores das revistas científicas.

As revistas científicas podem e devem colaborar nessa tarefa, estabelecendo recomendações éticas mais amplas e detalhadas a serem seguidas pelos pesquisadores que pretendam publicar os resultados de seus estudos.

A lgumas sugestões práticas, baseadas nas recomendações de Rennie e Yank $^{(9)}$ e de Amdur e Biddle ${ }^{(13)}$, poderiam ser adotadas pelos editores:

1. As orientações éticas contidas nas Instruções aos Autores de revistas devem ser mais amplas e claras do que as observadas atualmente.
2. As revistas devem citar explicitamente a Declaração de Helsinque e a Resolução 196/ 96 do Conselho Nacional de Saúde como referências para orientação aos pesquisadores.

3. As revistas devem publicar a Declaração de Helsinque (preferencialmente versão em português da última edição - 0 Conselho Federal de M edicina poderia patrocinar a tradução oficial desse documento internacional) e a Resolução 196/ 96 do Conselho Nacional de Saúde.

4. Os pesquisadores devem seguir, durante a elaboração e execução de seus estudos clínicos, a Declaração de Helsinque e a Resolução 196/ 96.

5. As revistas devem exigir que no texto dos artigos publicados, na parte de Métodos, os autores informem sobre 0 consentimento esclarecido e a aprovação prévia do protocolo por comitê de ética.

6. $\mathrm{Na}$ análise dos artigos enviados para publicação, os editores devem solicitar, quando necessário, informações adicionais sobre os aspectos éticos da pesquisa.

\section{REFERÊNCIAS}

1. Vieira S, H ossne WS. Um pouco de história. In: _____ Experimentação com seres humanos. 1 a ed. São Paulo: Editora Moderna, 1987;9-29.

2. Sussman MD. Ethical standards in the treatment of human subjects involved in clinical research [editorial]. J Pediatr Orthop 1998;18:701702.

3. Vollmann J, Winau R. Informed consent in human experimentation before the Nuremberg code. BMJ 1996;313:1445-1447.

4. The Nuremberg Code (1947). BMJ 1996;313:1448.

5. World Medical Association - Declaration of Helsinki. J AMA 1997; 277:925-926.

6. Conselho Nacional de Saúde - Ministério da Saúde. Diretrizes e normas regulamentadoras de pesquisa envolvendo seres humanos. Resolução 196, 1996.

7. Sardenberg T, M üller SS, Pereira HR, O liveira RA, H ossne WS. A nálise dos aspectos éticos da pesquisa em seres humanos contidos nas instruções aos autores de 139 revistas científicas brasileiras. Rev Assoc Med Bras 1999 (no prelo).

8. Internacional Committee of Medical J ournals Editors. Uniforms requeriments for manuscripts submitted to biomedical journals. J Pneumol 1997;23:XXV-XXXIV

9. Rennie $D$, Yank $V$. Disclosure to the reader of institutional review board approval and informed consent [editorial]. J AMA 1997;277:922-923.

10. Nilstun $T$, Rastam J. Ethics in orthopedic research [editorial]. Acta Orthop Scand 1997;68:205-206.

11. Einhorn TA, Burstein AH, Cowell HR. Human experimentation [editorial]. J Bone J oint Surg [Am] 1997;79:959-960.

12. Beecher HK. Ethics and clinical research. N Engl J Med 1966;274: 1354-1360.

13. A mdur RJ, Biddle C. Institutional review board approval and publication of human research results. J AMA 1997;277:909-914. 